\title{
Evaluation of thyroid function in a sample of newborns through different modes of delivery
}

\begin{tabular}{ccc}
\hline Sasan L. Hanna* & Awat I. Hamadamen** & Dlair A.K. Chalabi* \\
\hline Abstract
\end{tabular}

Background and objective: Congenital hypothyroidism is the most common preventable cause of mental retardation detected during early childhood. Its early diagnosis is crucial for a better outcome. Many factors are contributed to this problem including maternal, fetal and others. This study aimed to assess thyroid hormone status in relation to certain obstetrical especially mode of delivery and neonatal factors

Methods: A descriptive cross-sectional study conducted in postnatal care and delivery room (operative and vaginal) of Maternity teaching hospital in Erbil city. Ninety-two babies were included and subdivided into three groups according to their route of delivery. A thyroid stimulating hormone cut off value of 10 was selected as the upper normal level for the purpose of the study.

Results: A significant proportion of babies with cord thyroid stimulating hormone concentration more than $10 \mathrm{mIU} / \mathrm{L}$ (25 out of 92) were noticed, and this is near to many previous studies used the same cut off value. Mean of This hormone is relatively increased among newborns of the elective cesarean section while maternal total triiodothyronine and total thyroxine were higher within the elective group. Prenatal evidence of placental calcification and first born babies were associated with higher thyroid stimulating hormone levels.

Conclusion: Emergency cesarean section is less likely to be associated with elevated cord blood thyroid stimulating hormone level compared to other routes of delivery/but this is not confirmatory and recall test is recommended to exclude hypothyroidism.

Keywords: Congenital hypothyroidism; Hormone; Thyroid-stimulating hormone; Newborn.

\section{Introduction}

Congenital hypothyroidism is well known to be the most common preventable etiology of intellectual disability in the pediatric age group, constituting around $90 \%$ of hypothyroidism cases in young children. ${ }^{1}$ Etiology of congenital hypothyroidism could be sporadic or familial and even can be classified into goitrous, or nongoitrous. ${ }^{2}$ Thyroid hormones are crucial for normal development of the fetal central nervous system. During the period of brain growth, thyroid hormones help in many processes like migration, proliferation, and differentiation of neuronal cells. ${ }^{3}$ Even mild reduction in this hormone may lead to affect the proper brain development if it occurs during serious developmental periods. $^{4}$ Early treatment is usually preventable for intellectual abnormality but delay results in irreversible brain damage. The longer the disorder goes unrecognized (and thus untreated) the greater is the insult to the brain. ${ }^{1,5}$ Deficiency of maternal thyroid hormones during pregnancy may be the cause of such disease among fetus or newborn after birth. Incidence rate before the introduction of routine neonatal screening demonstrate reports of 1:7000$1: 10,000^{5}$, but after screening, the incidence worldwide has increased because of early detection and that (for example in India varies from 1:25002800 to $2.1: 1000$ live births). ${ }^{6}$ The situation

* Department of Pediatrics, College of Medicine, Hawler Medical University, Erbil, Iraq.

** Department of Obstetrics and Gynecology, College of Medicine, Hawler Medical University, Erbil, Iraq. 
in Iraq still not clear with few regional studies and most districts have no annual survey or routine screening for thyroid function. Over the period of 10 years, 45 children under 12 years diagnosed with hypothyroidism were encountered in Endocrine and Diabetes Clinic for Children in Al-Kadhymia Teaching Hospital College of Medicine, Al-Nahrain University Baghdad, Iraq. Five (11.1\%) patients had Hashimoto thyroiditis, and 40 (88.9\%) were diagnosed with congenital primary hypothyroidism. ${ }^{2}$ Many researchers have indicated the sample of cord blood Thyroid Stimulating Hormone (TSH) in term neonates as a screening test for congenital thyroid hypofunction. ${ }^{7,8}$ This screening tool is an attractive way because of its simplicity and accessibility. Fuse et al. recommended that mixed cord sample is a good technique for screening for hypothyroidism at birth. ${ }^{9}$ Even Walfish established that cord TSH level is more sensitive and specific as compared to cord or filter paper sample of thyroxine level (T4) at 3-5 days of age. It is therefore critical to make the newborns screened within three months of birth. If the initial results were a low level of T4 hormone and raised $\mathrm{TSH}$, additional/ samples/recommended to confirm a diagnosis of congenital hypothyroidism. ${ }^{1}$ Most authors endorse to repeat tests if initial were cord blood to confirm results. The recall percentages for confirmatory detection have been variable for example in India have recalled newborns with cord blood TSH levels of more than $20 \mu \mathrm{U} / \mathrm{L}^{7}$ while in Thailand have used value of 30 $\mathrm{mIU} / \mathrm{L}^{6}$ with recall rates of $(1.83 \%$ and $1.1 \%$ ) correspondingly with additional reduction to 0.43 and $0.42 \%$ if the cut off levels were increased to $40 \mu \mathrm{U} / \mathrm{L}$. Other recall rates were ranging between above $20 \mu \mathrm{U} / \mathrm{L}, 30$ and $40 \mu \mathrm{U} / \mathrm{L}$, respectively. Prognosis for the intellectual function is outstanding if treatment is started postnatal immediately or soon before one month of age. ${ }^{10}$ Fewer than $5 \%$ of those with congenital hypothyroidism are detected clinically initially, earlier than laboratory diagnosis. So the physician usually depends on newborn screening tests for the quick diagnosis. Regular screening is still not universal especially among developing countries like Iraq and Nigeria. ${ }^{8}$ Additional problems may be defect in visuospatial managing and selective memory and sensorimotor deficiencies. The emotional and economic impact on the parents and community can be lowered if the medication is started earlier. This is why quick neonatal discharges after birth, which is a common practice; necessitate the significance of cord blood TSH as a screening test/which should not be neglected. ${ }^{6}$ Some researchers reported that (labor pain, duration of labor, and uterotonic agents) had no influence on cord blood TSH and thyroid hormones but only the mean cord TSH in (vacuum extractions) was significantly greater than that of vaginal and cesarean deliveries. ${ }^{11}$ Most of the studies highlighted that the distinction between cord serum TSH results in different types of deliveries were temporary and the increase of cord TSH suggested delivery strain, which has no effect on TSH test on the $5^{\text {th }}$ day oflife. ${ }^{12}$ This study aimed to assess the effect of the mode of delivery on the thyroid function of newborns. Other specific objectives included assessing the effect of fetal, obstetric and demographic data on thyroid function.

\section{Methods}

A cross-sectional study was conducted over three months' period between $1^{\text {st }}$ July 2016 and $31^{\text {st }}$ September 2016 . The study included 92 newborn babies delivered by different modes in Maternity teaching hospital in Erbil (postnatal care and neonatal department), those with known maternal thyroid dysfunction, their mother receives regular drugs affecting thyroid function, obvious anomalies or prenatal evidence of systemic disorder were excluded from the study. The sample was subdivided into three groups according to the mode of delivery: vaginal (NVD), 
elective cesarean (ECS) and emergency cesarean section (EMCS). Data were collected through history taking including maternal and prenatal important details such as maternal disease, antenatal care, and medications. Thorough physical examination (general and systemic) was carried out on each neonate after birth and on subsequent follow-up visits, to ensure they were healthy and have no obvious abnormality. Apgar scores, weight, length, gestational age assessed by dates or ultrasound, gender, maternal problems (medical or obstetric), birth order and others were registered in the questionnaire form. The pregnant mothers were also assessed for goiter by palpation of the neck while they swallow, the researcher standing behind them during the examination. Prenatal history of thyroid abnormalities or previous ingestion of anti-thyroid medications were recorded. For this study, ethical approved was obtained from the ethical committee of the College of Medicine, Hawler Medical University. Written and verbal consent was taken from mothers or caregivers after discussing the aim of the study. Follow up written arrangements were consequently given to them about the next visit if the initial blood sample was equivocal or results highly suggestive of thyroid dysfunction after discussing the importance of the test. Umbilical cord blood plasma TSH concentration was measured using a two-site immunoenzymo-metric assay and triiodothyronine (T3), and thyroxine (T4) levels were measured using radioimmunoassay. For the present study, we used upper normal TSH level cut off point of more than 10 as abnormal as suggested in many studies regarding initial cord blood TSH. ${ }^{1,10,13-14}$ Initial TSH level can be classified into:

normal $(<10 \mathrm{mIU} / \mathrm{L})$

indeterminate $(10-40 \mathrm{mlU} / \mathrm{L})$

hypothyroid (>40 $\mathrm{mIU} / \mathrm{L}$ )

Blood Sampling: Two milliliters of umbilical (cord)blood was withdrawn by lightly milking a $15-20 \mathrm{~cm}$ length of the fetal side of the umbilical cord during the first five minutes after the birth of each baby. Two milliliters of venous blood was taken by venipuncture of a peripheral vein of the mother during the first 24 hours. The blood samples were collected into a plain sample bottle tube without added anticoagulant and then permitted to clot then was centrifuged. Later, the analysis was done for thyroid hormones (TSH, T4,T3).

Statistical analysis: Data were analyzed by the statistical package for the social sciences (version 23) using a Chi-square test to calculate the Pearson Chi-square to compare proportions. Fisher's exact test was used for small sized samples in the case when the Chi-square test is not suitable. One-way analysis of variance (ANOVA) was used to compare the means of the three groups. A $P$ value of 0.05 or less was considered to be significant.

\section{Results}

Among 92 newborns included in the study, $56(60.9 \%)$ were males, and 36 $(39.1 \%)$ were females with a male to female ratio of $1.6: 1$ (Figure 1). They were divided into three groups according to the mode of delivery for the aim of the study: 30 vaginal delivery, 30 EMCS and 32 ECS (Figure 2). The percentage of babies with cord TSH concentration of more than $10 \mathrm{mIU} / \mathrm{L}$ were 25 out of 92 . Data were analyzed using Chi-square to compare between proportions. Table 1 demonstrates sample distribution among different modes of delivery, and we can see that elective CS is unlikely finding in first-born babies compared to other modes. Fetal distress and maternal hypertension were higher significantly among emergency CS as expected as it may be an indication for the operation. Other obstetrical, neonatal and demographic data were not proportionally related to these deliveries. TSH level varies significantly between groups studied as high proportion of $\geq 10$ were in the vaginal delivery group followed by elective and lastly with a small percentage 
in emergency one. Descriptive analysis reveal mean neonatal TSH level was 9.50 $( \pm 12.27)$ with minimum value was
0.42 while maternal TSH mean was 2.90 $( \pm 3.37)$.

Table 1: Characteristics of the newborns of the studied sample within the groups.

\begin{tabular}{|c|c|c|c|c|c|}
\hline \multirow[b]{2}{*}{ Variables } & & \multicolumn{3}{|c|}{ Mode of delivery, $\mathrm{n}(\%)$} & \multirow[t]{2}{*}{$P$ value } \\
\hline & & $\begin{array}{l}\text { ECS } \\
n=32\end{array}$ & $\begin{array}{c}\text { EMCS } \\
n=30\end{array}$ & $\begin{array}{l}\text { NVD } \\
n=30\end{array}$ & \\
\hline \multirow[t]{2}{*}{ Gender } & Male & $20(62.5)$ & $20(66.7)$ & $16(53.3)$ & \multirow{2}{*}{0.556} \\
\hline & Female & $12(37.5)$ & 10(33.3) & $14(46.7)$ & \\
\hline \multirow[t]{3}{*}{ Weight in percentile } & $<10$ th PC & $2(6.3)$ & $2(6.7)$ & $1(3.3)$ & \multirow{3}{*}{$0.464^{*}$} \\
\hline & normal & $30(93.8)$ & $26(86.7)$ & $26(86.7)$ & \\
\hline & $>90$ th PC & $0(0)$ & $2(6.7)$ & $3(10)$ & \\
\hline \multirow[t]{3}{*}{ Length in percentile } & $<10$ th PC & $4(12.5)$ & $0(0)$ & $2(6.7)$ & \multirow{3}{*}{$0.169^{*}$} \\
\hline & normal & $22(68.8)$ & $26(86.7)$ & $26(86.7)$ & \\
\hline & $>90$ th PC & $6(18.8)$ & $4(13.3)$ & $2(6.7)$ & \\
\hline \multirow[t]{2}{*}{ Gestational age } & $<37$ weeks & $2(6.3)$ & $4(13.3)$ & $4(13.3)$ & \multirow{2}{*}{$0.646^{*}$} \\
\hline & $37-42$ weeks & $30(93.8)$ & $26(86.7)$ & $26(86.7)$ & \\
\hline \multirow[t]{2}{*}{ Time of cord clamp } & $\leq 3 \min$ & $30(93.8)$ & 30(100.) & 30(100.) & \multirow{2}{*}{$0.326^{*}$} \\
\hline & $>3 \min$ & $2(6.3)$ & $0(0)$ & $0(0)$ & \\
\hline \multirow[t]{3}{*}{ Birth order } & First & $2(6.3)$ & $10(33.3)$ & $13(43.3)$ & \multirow{3}{*}{0.011} \\
\hline & Second & $6(18.8)$ & $4(13.3)$ & $6(20)$ & \\
\hline & $>2$ & $24(75)$ & $16(53.3)$ & $11(36.7)$ & \\
\hline \multirow[t]{3}{*}{ Maternal disease } & $\mathrm{PIH} †$ & $2(6.3)$ & $6(20)$ & $0(0)$ & \multirow{3}{*}{$0.013^{*}$} \\
\hline & GDM† & $0(0)$ & $2(6.7)$ & $1(3.3)$ & \\
\hline & NONE & $30(93.8)$ & $22(73.3)$ & $29(96.7)$ & \\
\hline \multirow[t]{2}{*}{ APGAR1 } & $\geq 7$ & $20(62.5)$ & $18(60)$ & $21(70)$ & \multirow{2}{*}{0.702} \\
\hline & $<7$ & $12(37.5)$ & $12(40)$ & $9(30)$ & \\
\hline \multirow[t]{2}{*}{ APGAR5 } & $\geq 7$ & $24(75)$ & $26(86.7)$ & 28(93.3) & \multirow{2}{*}{$0.144^{*}$} \\
\hline & $<7$ & $8(25)$ & $4(13.3)$ & $2(6.7)$ & \\
\hline \multirow[t]{2}{*}{ Fetal distress } & YES & $0(0)$ & $6(20)$ & $0(0)$ & \multirow{2}{*}{$0.002^{*}$} \\
\hline & $\mathrm{NO}$ & $32(100)$ & $24(80)$ & $30(100)$ & \\
\hline
\end{tabular}

${ }^{*}$ Fisher exact test

† PIH; pregnancy-induced hypertension, GDM; gestational diabetes

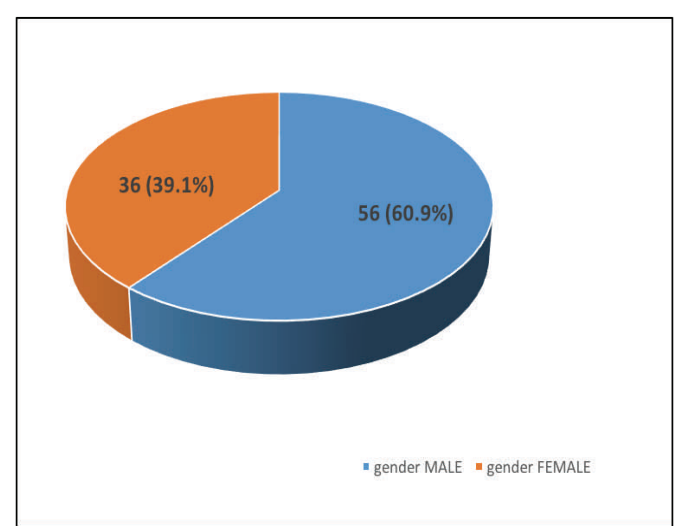

Figure 1: Gender distribution of studied newborns.

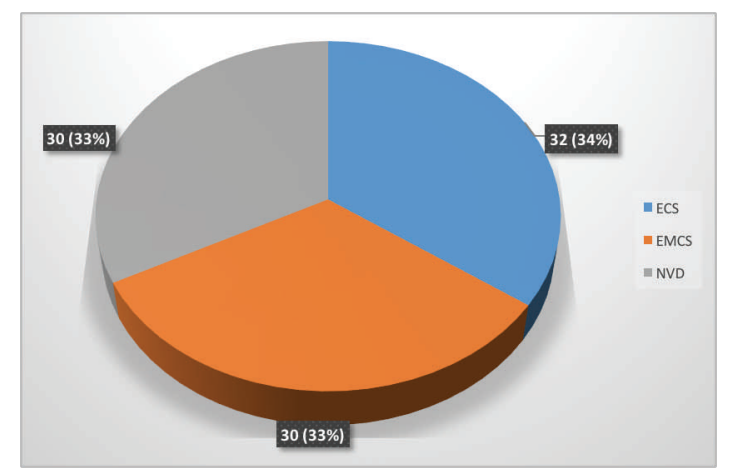

Figure 2: Percentage of modes of delivery among the studied sample (ECS; elective cesarean section, EMCS; emergency cesarean section, NVD; vaginal delivery). 
One-way ANOVA was used to compare means with their standard deviation. Table 2 shows that mothers who underwent vaginal delivery were significantly younger than other groups while the mean weight of their offspring was lower. No significant relation was found between neonatal thyroid function test and type of delivery but a significant relation of the mode of delivery to maternal T4, T3 and TSH was found. TSH level mainly increased among those undergoing EMCS while T4 and T3 were higher in pregnant women delivered through ECS.

Table 2: One way-ANOVA demonstrate the association of mean thyroid related hormones with different modes of delivery.

\begin{tabular}{|c|c|c|c|c|}
\hline Variables & $\operatorname{ECS}(a)$ & EMCS(b) & NVD(c) & $P$ value \\
\hline Maternal age & $30.81( \pm 4.43)$ & $30.06( \pm 5.84)$ & $26.40( \pm 5.79)$ & 0.004 \\
\hline Weight & $3.06( \pm 0.34)$ & $3.38(0 \pm .49)$ & $3.64( \pm 0.56)$ & $<0.001$ \\
\hline Maternal T4 $(\mathrm{nmol} / \mathrm{l})^{*}$ & $109( \pm 13.81) b$ & $95.68( \pm 19.38) a$ & $102.52( \pm 15.29)$ & 0.007 \\
\hline Maternal T3 $(\mathrm{nmol} / \mathrm{l})^{*}$ & $2.36( \pm 0.59) b$ & $1.72( \pm 1.07) a c$ & $2.11( \pm 0.38) b$ & 0.004 \\
\hline Maternal TSH $(\mathrm{mlU} / \mathrm{l})^{*}$ & $2.43( \pm 1.11) b$ & 4.17( \pm 5.49$) a c$ & $2.13( \pm 1.24) b$ & 0.038 \\
\hline Neonatal T4 (nmol/l) & $104.39( \pm 15.28)$ & $102.50( \pm 20.23)$ & $110.93( \pm 12.15)$ & 0.112 \\
\hline Neonatal T3 (nmol/l) & $0.77( \pm 0.78)$ & $0.94( \pm 1.09)$ & $0.60( \pm 0.19)$ & 0.250 \\
\hline Neonatal TSH (mIU/l) & $12.32( \pm 18.7)$ & $5.66( \pm 3.79)$ & $10.33( \pm 7.71)$ & 0.091 \\
\hline
\end{tabular}

\footnotetext{
${ }^{*} a, b$ and $c$ indicate which means are significantly different from each other via Post-Hoc tests (LSD)
} 
In Table 3, we can conclude that among all and all cases of prenatal evidence of modes of delivery, high neonatal TSH level $(\geq 10)$ is more among first or second born placental calcification seen by antenatal babies relatively to those birth order of $>2$ ultrasound had high TSH level $(\geq 10)$.

Table 3: Neonatal TSH and its association with different variables.

\begin{tabular}{|c|c|c|c|c|}
\hline \multirow[b]{2}{*}{ Variables } & & \multicolumn{2}{|c|}{ Neonatal TSH } & \multirow[b]{2}{*}{$P$ value } \\
\hline & & $\begin{array}{c}\leq 10 \\
\text { No. }(\%)\end{array}$ & $\begin{array}{c}>10 \\
\text { No. (\%) }\end{array}$ & \\
\hline \multirow[t]{3}{*}{ Mode of Delivery } & ECS & $22(68.8)$ & $10(31.3)$ & \multirow{3}{*}{0.005} \\
\hline & EMCS & $28(93.3)$ & $2(6.7)$ & \\
\hline & NVD & $17(56.7)$ & $13(43.3)$ & \\
\hline \multirow[t]{3}{*}{ Weight for PC } & $<10$ th centile & $4(80)$ & $1(20)$ & \multirow{3}{*}{$0.266^{*}$} \\
\hline & normal & $61(74.4)$ & $21(25.6)$ & \\
\hline & $>90$ th centile & $2(40)$ & $3(60)$ & \\
\hline \multirow[t]{3}{*}{ Length for PC } & $<10$ th centile & $4(66.6)$ & $2(33.3)$ & \multirow{3}{*}{$0.446^{*}$} \\
\hline & normal & $56(75.7)$ & $18(24.3)$ & \\
\hline & $>90$ th centile & $7(58.3)$ & $5(41.7)$ & \\
\hline \multirow[t]{2}{*}{ Gestational Age } & $<37$ & $6(60)$ & $4(40)$ & \multirow[b]{2}{*}{0.334} \\
\hline & $37-42$ & $61(74.4)$ & $21(25.6)$ & \\
\hline \multirow[t]{2}{*}{ Time of cord clamping } & $\leq 3 \min$ & $65(72.2)$ & $25(27.8)$ & \multirow{2}{*}{$1^{*}$} \\
\hline & $>3 \min$ & $2(100)$ & $0(0)$ & \\
\hline \multirow[t]{3}{*}{ Birth order } & First & $15(60)$ & $10(40)$ & \multirow{3}{*}{0.021} \\
\hline & Second & $9(56.3)$ & $7(43.8)$ & \\
\hline & $>2$ & $43(84.3)$ & $8(15.7)$ & \\
\hline \multirow[t]{3}{*}{ Maternal disease } & Hypertension & $8(100)$ & $0(0)$ & \multirow{3}{*}{$0.097^{*}$} \\
\hline & Diabetes & $3(100)$ & $0(0)$ & \\
\hline & None & $56(69.1)$ & $25(30.9)$ & \\
\hline \multirow[t]{4}{*}{ Prenatal US } & Polyhydramnios & $3(60)$ & $2(40)$ & \multirow{4}{*}{$0.024^{*}$} \\
\hline & Oligohydramnios & $6(66.7)$ & $3(33.3)$ & \\
\hline & Placental calcification & $0(0)$ & $3(100)$ & \\
\hline & Normal & $58(77.3)$ & $17(22.7)$ & \\
\hline \multirow[t]{2}{*}{ APGAR 1 minute } & $\geq 7$ & $44(74.6)$ & $15(25.4)$ & \multirow[b]{2}{*}{0.614} \\
\hline & $<7$ & $23(69.7)$ & $10(30.3)$ & \\
\hline \multirow[t]{2}{*}{ APGAR 5 minutes } & $\geq 7$ & $58(74.4)$ & $20(25.6)$ & \multirow{2}{*}{0.435} \\
\hline & $<7$ & $9(64.3)$ & $5(35.7)$ & \\
\hline \multirow[t]{2}{*}{ Fetal distress } & Yes & $4(66.7)$ & $2(33.3)$ & \multirow{2}{*}{$0.661^{*}$} \\
\hline & No & $63(73.3)$ & $23(26.7)$ & \\
\hline
\end{tabular}

${ }^{*}$ Fisher exact test 


\section{Discussion}

The present study used upper normal cord TSH level cut off of more than 10 as abnormal as mentioned before, other studies may use different higher concentration according to their national program of screening. Normal cord TSH values show a wide range from 1.0 and may even reach up to $28.9 \mathrm{mlU} / \mathrm{l}$ from birth till the fourth day in term babies. ${ }^{1}$ Mean neonatal TSH level was $9.50 \pm 12.27$ while maternal TSH was far lower and other hormones mean levels were within normal range. The high percentage of those with $\mathrm{TSH}>10 \mathrm{mIU} / \mathrm{L}$ group may not be a major problem as normal upper limit values may reach up to 30 but need to be evaluated by further studies as first cord sample usually have lower concentration compared to next days. ${ }^{8}$ Nearly such levels $(33.6 \%$ and $35.56 \%$ ) were founded in Manipur ${ }^{1}$ and $\mathrm{Nepal}^{15}$ consecutively. Mean weight was higher within the vaginally delivered babies while this was not the case regarding the mean length. When we plot weight and length on percentile, no evidence of significant association noticed even with thyroid assessment tests. Hyman SJ et al. support the idea that endocrine disorders especially hypothyroidism is more common among preterm, low birth weight (LBW) babies. ${ }^{16}$ Sometimes cases may be missed because of delayed elevation of TSH in premature and LBW infants, that were not excluded in this recent study. ${ }^{10}$ Prematurity is not a contributing factor related to congenital hypothyroidism as revealed in results but only may delay the diagnosis because of low initial TSH levels. This agrees with Amash et al. in a study conducted in Baghdad during a one-year period with the incidence of high TSH level was $2 \%$ among preterm compared to full-terminfants $(0.7 \%)$ among vaginally delivered babies and even lower among the operated group with no strong association. ${ }^{17}$ Tehrani et al. declared that there is no relation of gestational age with TSH and other thyroid hormones in a study included 90 newborns/in postnatal care unit in Kowsar hospital in Qazvin, Iran. ${ }^{12}$ The study designed to detect any abnormal neonatal thyroid tests to different modes of childbirth but no significant results compared to strong association with maternal thyroid dysfunction (T3, T4, TSH) as it is higher within the elective group. Contradicting what Amash et al. reported that type of delivery is not related when studied TSH level only. ${ }^{17}$ International journal of endocrinology and metabolism published an article stated that different styles of delivery significantly and even highly associated with TSH, T4 and T3 level (all were higher within the elective group) which support these study findings. Some other previous studies revealed that there was no relation between cord thyroid hormone values and the delivery route, labor duration or using uterotonic medications. ${ }^{18}$ Many researchers ${ }^{19,20}$ concluded there is no statistically significant difference between the total cord T3 and T4 levels in newborns and their mothers following either vaginal or ECS, but the difference may become significant after recall test a few days later. Those with assisted deliveries had higher median TSH levels as compared with unassisted deliveries. The group of infants born via ECS had higher TSH levels of borderline statistical significance. ${ }^{20}$ The increase in serum thyrotropin level during the early minutes after birth is due to exposure of neonates to the cold extrauterine environment. Infants delivered by cesarean section have lower axillary, and skin temperature than those delivered per vaginum. Therefore, the lower body temperature of the neonate in the cesarean section may be a stimulus for the higher TSH levels, which evokes increased secretion of T4 and T3 by the thyroid. ${ }^{10}$ No history of fetal distress and a low Apgar score is associated with the type of childbirth or thyroid function abnormality. Few studies demonstrate the effect of fetal distress with the route of delivery, but Apgar score was studied and was not of important value in relation to thyroid 
function tests. ${ }^{12}$ Previous data suggest that lower T4 and T3 levels are mainly due to lower TSH levels in asphyxiated newborns (Apgar score less than 7); also, peripheral metabolism of T4 in asphyxiated neonates (low Apgar) can be reformed due to low T3. ${ }^{21,22}$ Neonates of mothers giving birth to their first child had higher TSH concentrations compared to mothers who were multiparous ${ }^{22,23}$, but this was result in this study as firstborn babies have higher TSH levels and this may be attributed to choosing the upper limit of $10 \mathrm{mU} / \mathrm{ml}$. Maternal disease during pregnancy and blood glucose were variable significantly among the studied sample, but only evidence of placental calcification through ultrasound was the only factor that affects and may lead to abnormal thyroid performance in offspring. No available previous studies $^{22}$ support this, but we can explain it through the relation of fetal distress with placental calcification. Although no relation was founded in this study between neonatal thyroid hormones and gestational diabetes and hypertension, Herbstman et al. showed Infants of maternal gestational induced hypertension and or preeclampsia had a significant reduction in umbilical cord total and free T4 level. ${ }^{20}$

\section{Conclusion}

High cord blood TSH level (> $10 \mathrm{mlU} / \mathrm{L}$ ) were noticed in large proportions of screened newborns mainly those products of ECS and vaginal delivery compared relatively to emergency one, but this needs recall test after few days to exclude hypothyroidism.

\section{Competing interests}

The authors declare that they have no competing interests.

\section{References}

1. Sangeeta N, Kamala L, Karki $P$, Basar G, Kumar YI, Singh LR, et al. Assessment of umbilical cord TSH in term neonates in Manipur. IOSR-JDMS 2013; 9(1):14-7.
2. Nasheiti NA. Childhood hypothyroidism in Iraq: A retrospective study. Int $\mathrm{J}$ Endocrinol Metab 2005; 3:136-9.

3. Bernal J. Thyroid hormones and brain development. Vitam Horm 2005; 71:95-122.

4. Zoeller TR, Dowling AL, Herzig CT, lannacone EA, Gauger KJ, Bansal R. Thyroid hormone, brain development, and the environment. Environ Health Perspect 2002;110(Suppl 3):35561.

5. John J, Abraham A, Sahu S. Umbilical cord blood TSH: a predictor of congenital hypothyroidism. Indian J Physiol Pharmacol 2013; 57(4):452-3.

6. Sanghvi U, Diwakar KK. Universal newborn screening for congenital hypothyroidism. Ind Pediatr 2008; 45:331-2.

7. Manglik AK, Chatterjee N, Ghosh G. Umbilical cord blood TSH levels in term neonates: A screening tool for congenital hypothyroidism. Indian Pediatr 2005; 42: 1029-32.

8. Ugege MO, Airede KI, Jiya NM. Thyroid function profile in cord blood and postnatal changes at 24 and 72 hours in healthy term Nigerian neonates. Niger J Paed 2014; 41(3):209-14.

9. Fuse Y, Wakae E, Nemoto Y, Uga N, Tanaka M, Maeda M, et al. Influence of perinatal factors and sampling methods on TSH and thyroid hormone levels in cord blood. Endocrinol Jpn 1991; 38(3):297-302.

10. Rose SR, Brown RS, Wilkins L. Update of Newborn screening and therapy for congenital hypothyroidism. Pediatrics 2006; 117: 2290-303.

11. Shi LX, Ma QL, Zhang JX. Influence of perinatal factors and sampling methods on thyroid stimulating hormone and thyroid hormone levels in cord blood. Zhonghua Fu Chan KeZaZhi 1994; 29:714-6.

12. Tehrani FR, Aghaee M, Asefzadeh S. The comparison of thyroid function tests in cord blood following cesarean section or vaginal delivery. Int J Endocrinol Metab 2003; 1:22-6.

13. Devi AR, Naushad SM. Newborn screening in India. Indian Pediatr 2004; 71:157-60.

14. Kaur G, Srivastav J, Jain S, Chawla D, Chavan BS, Atwal R, et al. Preliminary report on neonatal screening for congenital hypothyroidism, congenital adrenal hyperplasia and glucose6-phosphate dehydrogenase deficiency: A Chandigarh experience. Indian J Pediatr 2010; 77:969-73.

15. Agrawal K. Levels of T4 and TSH in mothers and newborns. Health Renaissance 2013; 11(1):6-10.

16. Hyman SJ, Novoa Y, Holzman I. Perinatal endocrinology: Common endocrine disorders in the sick and premature newborn. Pediatr Clin North Am 2011; 58(5):1083-98.

17. Ammash SI, Aldoree F, Sulaiman TI, Al-Jumaily A, Mahmood. Pilot study on neonatal screening for congenital hypothyroidism in Iraq. Fac Med Baghdad 2008; 50(4):416-9. 
18. Eltom A, Eltom $M$, Idris $M$, Gebre-Medhin $M$. Thyroid function in the newborn in relation to maternal thyroid status during labour in a mild iodine deficiency endemic area in Sudan. Clin Endocrinol (Oxf) 2001; 55:485-90.

19. Oken E, Braverman LE, Platek D, Mitchell ML, Lee SL, Pearce EN. Neonatal thyroxine, maternal thyroid function, and child cognition. J Clin Endocrinol Metab 2009; 94(2):497-503.

20. Herbstman J, Apelberg BJ, Witter FR, Panny S, Goldman LR. Maternal, infant, and delivery factors associated with neonatal thyroid hormone status. Thyroid 2008; 18(1):67-76.

21. Pereira DN, Procianoy RS. Effect of perinatal asphyxia on thyroid hormones. J Pediatr (Rio J) 2001; 77(3):175-8.

22. Gupta A, Srivastava S, Bhatnagar A. Cord blood thyroid stimulating hormone level - interpretation in light of perinatal factors. Indian Pediatr 2014; 51(1):32-6.

23. Zoeller RT, Rovet J. Timing of thyroid hormone action in the developing brain: clinical observations and experimental findings. J Neuroendocrinol 2004; 16:809-18.

24. Joseph R, Aw TC, Tan KL. Free thyroxine as a supplement to thyrotropin in cord screening for hypothyroidism. Ann Acad Med 1993; 22(4):549_ 52. 